Article

\title{
Sport for Development and Peace and the Environment: The Case for Policy, Practice, and Research
}

\author{
Richard Giulianotti ${ }^{1,2, *}$, Simon Darnell ${ }^{3}$, Holly Collison ${ }^{4}$ and P. David Howe ${ }^{1}$ \\ 1 School of Sport, Exercise and Health Sciences, Loughborough University, Loughborough, \\ Leicestershire LE11 3TU, UK; p.d.howe@lboro.ac.uk \\ 2 Department of Sports, Physical Education and Outdoor Studies, University of Southeast Norway, \\ Bø 3800, Norway \\ 3 Faculty of Kinesiology \& Physical Education, University of Toronto, Toronto, ON M5S 1A1, Canada; \\ simon.darnell@utoronto.ca \\ 4 Institute of Sport Business, Loughborough University, London E15 2GZ, UK; h.collison@lboro.ac.uk \\ * Correspondence: r.giulianotti@lboro.ac.uk; Tel.: +44-1509-226350
}

Received: 6 June 2018; Accepted: 20 June 2018; Published: 29 June 2018

\begin{abstract}
This paper highlights the need for critical attention and reflection within the Sport for Development and Peace (SDP) sector regarding the physical environment. Drawing on fieldwork that examined a variety of SDP initiatives in five different countries, we argue that instrumental concerns at local levels often mean that the physical environment takes a back seat to other development priorities within SDP activity. This is despite the critical importance of issues, such as environmental degradation and the threats posed by climate change, as well as the fact that sport is directly linked to the United Nations' Sustainable Development Goals and the 2030 Agenda. After providing examples of the relegation of the physical environment in different SDP contexts, we put forth three conceptual frameworks that would be useful within SDP scholarship for advancing critical discussion on this issue within the sector. The final section discusses both the implications of these initial findings and suggests questions and topics for future research around this timely issue.
\end{abstract}

Keywords: sport; development; peace; environment; sustainability; Sustainable Development Goals

\section{Introduction}

In this paper, we examine the relevance and place of the physical environment within the Sport for Development and Peace (SDP) sector. It is important, here at the outset, to articulate what we mean by both environment and SDP. On the environment, we follow Ingold who suggests, 'my environment is the world as it exists and takes on meaning in relation to me, and in that sense, it came into existence and undergoes development with me and around me' [1]. In the specific context of this paper, we use the term physical environment as the adjective 'physical' specifies the segment of Ingold's articulation that is of primary interest for this paper. Related to this, we see environmentalism as a broad philosophy and social movement on how human activity can limit harm to the physical environment. On the definition of Sport for Development and Peace, we follow the lead of the Commonwealth Secretariat, which states that SDP is, 'the intentional use of sport and physical activity as a tool to contribute to development and peace goals, including the Commonwealth goals of democracy and development' [2].

SDP has been a fast-growing area of global social and political activity since the early 1990s. The goals of SDP programmes regularly include peacebuilding and conflict resolution, empowering of girls and women, health promotion, and crime reduction, as well as promoting education, employment, and training. Many types of stakeholders participate in this work, notably, Non-Governmental 
Organizations (NGOs), governmental and intergovernmental bodies, corporations, private donors, and sport federations. Most SDP activity centres on intervention-based programmes implemented by NGOs in low- and middle-income countries, with considerable social scientific research having been undertaken in this area since the mid-2000s, notably, on the themes of youth, gender, peacebuilding, and health [3-7].

However, the physical environment is a major theme in both the research and practice of international development that has been largely neglected by both SDP stakeholders and scholars. As we show below, this oversight is reflected in the, often-marginal, status afforded to environmental issues within programmes, campaigns, and initiatives that take place within the SDP sector, as well as the general paucity of SDP research that focuses on the physical environment. In broad terms, it seems that the SDP sector has been, and largely continues to be, centred on the intersubjective world, in terms of what people do with and to each other, rather than on social relationships with the physical world, in terms of what people do to and with these surrounding environments.

In what follows, we seek to offer an initial contribution towards filling the gap in SDP research concerning the physical environment. To that end, we advance the first social scientific statement on the environment, with respect to SDP, and identify several ways in which the sector could engage with this crucial development theme. As we explain, our analysis seeks also to contribute to the small, but growing, body of social scientific work on the environment within sport and, at the same time, to assist the development of an understanding of how the field of sport studies may enhance our knowledge of environmental issues.

The paper is, thus, intended to act as a call for the global SDP sector, and the academics who study to it, to 'catch up' with the rest of the international development field, with respect to the physical environment. Climate change has been a recognized global political issue since at least the late 1960s; its entry into formal international politics was signalled by the landmark United Nations (UN) Conference on the Human Environment in Stockholm in 1972. Since this period, scientific research and 'green' political activity has greatly increased transnational awareness of (un)sustainable development, pollution, and global warming, and of the environmental damage and risks associated with climate change, such as extreme weather, rising sea levels, water shortages, the loss of biodiversity, and the destruction of eco-systems. The global scientific and public spheres also, generally, recognize that so-called 'developing' and marginalized communities have been the most severely affected by these forms of environmental damage and are likely to suffer the most in future as the impact of climate change becomes more acute. These are, of course, the very communities in which most SDP activities and research are focused. In broad terms, political responses to these global environmental crises have been relatively slow and ineffective [8].

With these justifications in mind, the remainder of the paper is organized into four main parts. Next, we examine the contexts for the paper, in both academic, political, and policy terms, with particular reference to the relative lack of scholarly research on the physical environment in SDP, alongside the, potentially, critical role played by the UN and the Sustainable Development Goals (SDGs) in driving future activity and study in this area. Following this, we explain the methods that we used in our research and then turn to set out the findings from our fieldwork in five different countries to open discussions of the conceptualization, positioning, and effects of environmental issues within the current SDP sector. The final section discusses both the implications of these initial findings and, perhaps, more importantly, suggests questions and topics for future research into SDP and the physical environment.

\section{Contexts}

To explain the context for our analysis of SDP and the physical environment, we need to set out both the academic and the political and policy backgrounds. The latter focus reflects the global political and policy basis of both the SDP sector and transnational environmental issues; it also registers how 
these political and policy dimensions may be both a catalyst and an area of study for future research into SDP and the physical environment.

\subsection{Academic Context}

The academic context for the paper is based on some significant areas of prior research, but also, as we explain, on substantial gaps in the literature. In terms of existing academic literature, the paper is best located in the relatively small, but growing, body of work on global sport and the physical environment. This literature has examined, for example, the relationship of the International Olympic Committee (IOC) to green issues, particularly as the environment was established as the 'third pillar' of Olympism in 1994, alongside sport and culture [8-11]. In addition, the environmental politics of sport development (meaning the development of the sport sector itself) has emerged as an important topic, such as in the construction of golf courses, where ecologically modernist approaches to overcoming environmental challenges have tended to usurp broader discussions about the sport's overall negative environmental impact [12]. More recently, critiques of 'green washing' in sport have emerged, charging that the corporate sports industry is committed primarily to the appearance of environmental responsibility, but in practice does little to contribute to advancing environmental sustainability [8]. This paper seeks to open the SDP sector, and the study thereof, to this wider body of critical work on sport and the physical environment. In this sense, we support the broad argument of Mallen that environmental sustainability is a fundamentally global issue that has been spotlighted by the UN, and that has definite ramifications for sport and, by extension, the field of SDP [13].

Crucially, however, the paper seeks to address a critical gap in the SDP literature. In short, there has been no detailed research or discussion on the physical environment within the academic literature on SDP. This lacuna may be partly explained by the way in which the SDP sector has largely passed over the environment as an issue for policy rather than practice. In prior contributions to academic and policy forums, we have argued that the SDP sector needs to take the physical environment more seriously, especially given the environmental focus of the SDGs [14-16]. This paper seeks to move SDP research much more concertedly in that direction.

One further benefit here is that such a focus may contribute towards the SDP literature 'catching up' with mainstream social science, where closer attention has been paid to environmental issues. Perhaps the most influential work in this regard was provided by Ulrich Beck through his theories of 'risk society', highlighting, in part, the transnational scope of global warming and other contemporary, humanity-made risks [17]. Further significant, critical, social scientific analyses of environmental issues have been advanced by many other scholars [18-21]. This literature also reminds us of the political and policy significance of the physical environment, and it is to these issues that we now turn.

\subsection{Political and Policy Contexts}

In the context of global politics and policy, the UN would play a key role in any move towards an environmental turn within SDP, particularly through its 2030 SDGs. The UN has been a highly influential force within SDP, having acted as its most prominent political advocate since at least the early 2000s. For example, the UN established the UN Office of Sport for Development and Peace (UNOSDP) in 2001, and named 2005 as its International Year of Sport and Physical Education. Accordingly, a large volume of SDP activity, especially in low- and middle-income countries, has been dedicated to pursuing the UN's development agenda, primarily framed by the Millennium Development Goals, which ran from 2000 to 2015, before the announcement of the SDGs.

Although the UNOSDP closed in 2017, many UN agencies, such as United Nations Children's Fund (UNICEF), United Nations Educational, Scientific and Cultural Organization (UNESCO), and United Nations High Commissioner for Refugees (UNHCR), continue to engage actively within the SDP sector. Moreover, the UN's SDGs feature a powerful endorsement of sport's role in promoting global development. Article 37 of Transforming our world: The 2030 Agenda for Sustainable Development reads: 
Sport is also an important enabler of sustainable development. We recognize the growing contribution of sport to the realization of development and peace in its promotion of tolerance and respect and the contributions it makes to the empowerment of women and of young people, individuals and communities as well as to health, education and social inclusion objectives. [22]

Crucially, the environment is a major strand running through the SDGs, to a much greater extent than in the earlier MDGs. The SDGs feature 17 goals that are summarized in the text Box 1 below:

Box 1. United Nations Sustainable Development Goals.

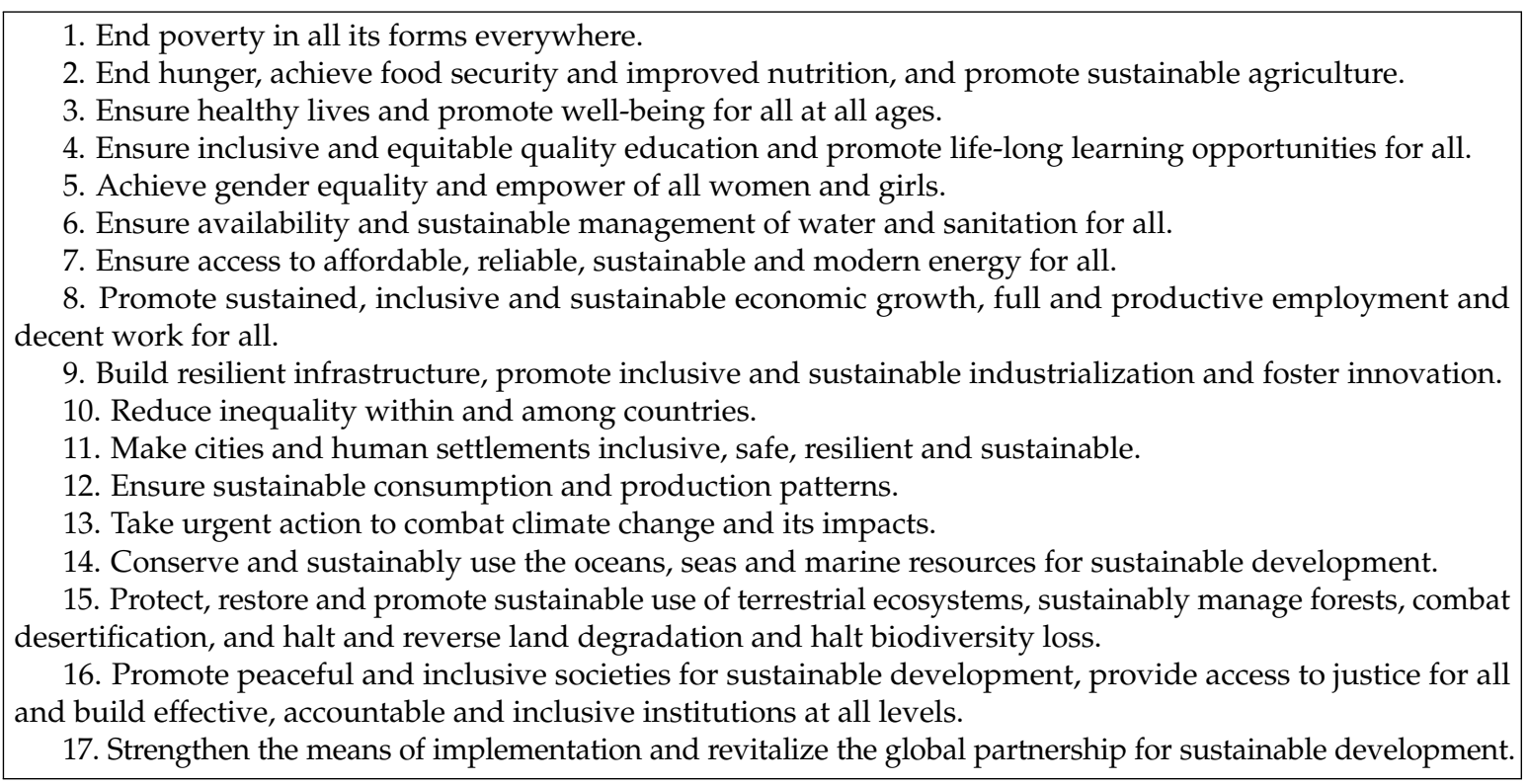

At least 12 of these goals have profound implications for the physical environment. The most obvious cases relate to SDGs $6,7,13,14$, and 15, concerned with securing water and sanitation, sustainable energy, combatting climate change, conserving natural water environments and resources, and protecting ecosystems, respectively.

Many other SDGs connect directly to the physical environment as well. SDGs 1 and 2 relate to agriculture and food security, which are threatened by climate change and environmental degradation; SDG 3, ensuring health and well-being, is directly threatened by pollution; SDGs 9, 11, and 12 relate to sustainable industrialization, housing, production, and consumption, respectively, which depend heavily on environmental protection; and, given the environment's role within the other goals, SDG 17 would mandate the participation of environmental organizations in global partnerships working towards sustainable development. Finally, in broader terms, green issues impinge upon all SDGs, notably, when considering global climate change, and the impacts and risks of environmental degradation and pollution.

Since their announcement, the SDGs have become an important driver for SDP advocates, particularly at the level of global advocacy and policy. A good example is the Commonwealth Secretariat, who recently used the SDGs as a conceptual framework through which to consider sport's potential contributions to development. According to the Commonwealth, sport's inclusion within the UN's 2030 agenda, "represents an important milestone for sport and an opportunity to build on previous commitments and progress made by the Commonwealth, the United Nations, and other international, national, and local stakeholders" [23]. The Commonwealth also recognizes six of the SDGs as being particularly compatible with sport, and offering sites at and through which sport can make a contribution to sustainability. However, these six SDGs identified by the Commonwealth (3-ensure health lives, 4-ensure quality education, 5-achieve gender equality, 
8-promote sustainable economic growth, 11-make cities inclusive and sustainable, 16-promote peaceful and inclusive societies), arguably do not have the strongest connection to the physical environment and environmentalism, suggesting that there is still room and a need to connect sport and SDP to the challenges of environmental sustainability.

In this sense, while recognizing the significant impact of the SDGs on the SDP sector, questions remain about whether, or at least to what extent, issues of the physical environment are being addressed and implemented within current SDP activities. It is important to acknowledge that, despite global recognition of the significance and importance of climate change, acting on it remains an often contestable and distinctly political activity within many practices of international development $[24,25]$. In other words, 'pro-green' activity in development is subject to complex political processes and influences. In the field of SDP, there are, at least, three such issues to consider.

First, some SDP stakeholders, particularly those focused on the ostensibly core competencies of the sector, like gender empowerment and health promotion, assert that the physical environment is, 'not our concern'. We received an early indication of this outlook when we attended a meeting of leading international SDP stakeholders in early 2015 to discuss the collective response to the anticipated SDGs. This group of stakeholders largely passed over the environmental content of the SDGs, judging this to be 'not relevant' for SDP, despite the obvious centrality of such issues to the SDGs. While it is important to recognize that the relatively small NGOs involved in specific types of interventions, such as peace-building or gender empowerment, may place the physical environment low on their list of development issues and priorities, such an approach is, arguably, becoming increasingly untenable, particularly for larger international SDP organizations or those working in communities that are already experiencing the effects of pollution, climate change, or wider environmental damage. This raises the subsequent question for SDP stakeholders, particularly NGOs, over how they might 'mainstream' the physical environment in their programme goals and activities, as well as into any special events or partnership work that they undertake [26,27].

Second, the SDGs harbour some inherent political challenges for the environment due to tensions and competing interests across the different goals. For example, several SDGs centre on modernization processes, such as economic growth, industrialization, urbanization, production and consumption, and reliable energy. These broad modernization processes have, arguably, been the main causes of global warming and environmental degradation, as marked by pollution, deforestation, destruction of living species and ecosystems, and climate change. Thus, at some level, these expansionist modernization goals represent direct threats to SDG environmental goals, particularly 6, 13, 14, and 15. Reconciling these tensions will be very challenging across the global political and economic system, let alone for resource-stretched NGOs in the SDP sector. In this sense, while they provide an important platform for addressing environmental issues within SDP, the SDGs also contribute to the emerging political divisions and policy tensions within the sector and much more widely. We return to these issues in more detail in the Discussion section.

Third, the 'health' of the physical environment is clearly not a straightforward issue, socially or politically, but instead a highly contested and multi-textured field involving diverse stakeholders with varied ideologies and interests. Stakeholders range from 'deep green' ecology movements to pro-growth national and international governmental organizations to private industrial corporations and even climate change sceptics. These competing and conflicting interests also appear in sport contexts: For example, at sport mega-events, environmental and community campaign groups often stage protests against corporate sponsors (such as energy and mining companies) for undertaking work that harms local eco-systems [28,29]; local communities and activists may oppose the transformation of local environments and the use of scarce natural resources to create sport stadiums or golf courses; and the labour and human rights of athletes, coaches, sport officials, and the media may be compromised by the staging of sport events in locations with high levels of air pollution. It is to be expected, then, that the SDP sector, like the wider sport or development fields, respectively, will be marked by political debates, differences, and disputes when addressing environmental issues 
at all levels. With this in mind, we turn to set out the methods for our research project, and, then, to explore the findings from our fieldwork as part of a global, comparative assessment of the SDP sector. These findings help to illustrate the ways in which the environment is understood-including by its absence-within the concepts and practices of SDP.

\section{Methods}

This current research project, from which emerges the following analysis and discussion of environmental issues in relation to SDP, was undertaken in five countries: Jamaica, Kosovo, Rwanda, Sri Lanka, and Zambia. These locations were chosen as regionally and culturally distinct, and, thus, became the foci of a systematic, comparative, multi-site research project conducted over three years (2014-2017). The broad goal of the study was to investigate the organization and implementation of the SDP sector at both global and local levels. In addition, the project sought to pay specific attention to three thematic areas: The conceptualization and implementation of human rights in and by SDP, the various ways in which peacebuilding through sport is approached, and the extent to which SDP responds to the needs of people with disabilities. Each researcher made at least two research visits to their allocated location(s), during which observations and broader ethnographic fieldwork were undertaken. This fieldwork utilized the classic qualitative research methods of participant observation, semi-structured interviews, and focus groups [30,31]. That said, the specific methods utilized in each location differed in some cases, often based on the context and situation encountered 'in the field.' In one location, a member of the research team participated fully in the delivery of an SDP programme as a volunteer, while, in another location, a research team member was asked to adopt a consultancy role to support local programming. In all cases, however, members of the research team could embed themselves within the local SDP sector, gaining insights into the politics, policies, and practices occurring there.

This research process resulted in data being collected from over 30 SDP programmes, as well as insights accrued into the wider social and political settings in which SDP takes place. Interviews and focus groups were conducted with over 200 key SDP stakeholders, notably, NGO officials and volunteers; SDP programme user groups and wider community members (e.g., parents); officials from national government, sport clubs and federations, and intergovernmental organizations; donors, ranging from global corporations to local community members; and further stakeholders, such as sport coaches, journalists, and academics. Most interviews were undertaken with the most prominent categories of stakeholder with the SDP sector, specifically, NGO officials, volunteers, and user groups, as well as officials from intergovernmental organizations, national government, and sport federations and clubs. Interview numbers were spread relatively evenly across all five study locations, although research in Zambia placed a greater emphasis on fieldwork.

Additional research was also undertaken into the organizational construction and implementation of the global SDP sector through fieldwork and interviews conducted at international SDP conferences in Europe and North America, and by visiting the headquarters of leading international SDP stakeholders, particularly intergovernmental organizations who advocate for SDP, global funders of SDP, and SDP policy makers.

Based on this comprehensive data collection, the results reported in this paper emerged somewhat organically. As fieldwork developed, we began to appreciate the extent to which issues of environmental sustainability were, generally, overlooked and rarely discussed within SDP, particularly at a local level. In response, we began to turn our attention to understanding: (a) Whether, or at least to what extent, the physical environment was indeed an issue within the SDP sector in each of the five locations, (b) the reasons, in turn, why the physical environment was overlooked, and the processes (social, historical, political, etc.) that might help to account for or explain this; and (c) the gaps in SDP policy and programming that exist as a result. The following sections offer an overview of these findings. 


\section{Findings}

As mentioned above, while not the initial or main thematic concentration of the study, the physical environment emerged as an important theme within the overall research project for several reasons. First, the announcement of the SDGs lent an increased importance to the issue of the environment and sustainability in international development, generally, and in the field of SDP, specifically. Second, the physical environment often intersected with SDP programmes in unexpected ways within the five locations studied; for example, at the micro level, the physical environment contributed to the production of particular kinds of sporting practices and experiences within SDP [32]. Third, in some cases the physical environment was largely absent from the policies and practices of SDP, a significant result in and of itself. In the remainder of this section, we offer illustrations of these initial insights by exploring the significance of the physical environment and its relation to (or its omission from) the SDP provision within our five locations. It is worth noting the countries are organised below in alphabetical order and this order has no bearing on the success or failure of the nation's SDP sector in dealing with environmental issues. The cross-cultural points raised in this section can, however, provide the basis for a discussion of politics, theory, and the need for future environmentally-focused research within SDP.

\subsection{Jamaica}

Within the five national locations analysed in this study, Jamaica emerged as an important and instructive case study, with respect to the environment and ecological sustainability, primarily because such issues were not regularly discussed or highlighted within SDP activity or policy. Instead, our fieldwork found that the main issues undertaken by SDP organizations in Jamaica-and, primarily, in the city of Kingston-were child resilience, anti-violence, support for people with a disability (particularly children and youth), and positive youth development. Within these activities, the question of how to mitigate the negative environmental impact of sport, or to use sport to promote environmental sustainability, was rarely discussed. This is even though the United Nations Development Programme (UNDP) recognizes that environmental issues, most notably climate change, are central to Jamaican development and that, already, "Jamaica suffers huge economic losses as a result of the environmental effects of climate change" [33]. As a result, the UNDP is working to support capacity building and adaptation programmes in rural communities across the island.

The fact that development activities focused on climate change, ecology, and sustainability are taking place in Jamaica, but are rarely implemented in conversation with SDP activity in the country, suggests something of an ongoing disconnect between SDP and the broader international development sector [34]. It also raises the possibility that, for those working in sport and SDP, environmentalism is still not seen as a priority development issue or the issue to which sport-based development programmes are best suited to contribute.

At the same time, environmentalism and the threats posed to climate change are recognized and discussed (albeit briefly) in Jamaica's 2011-2016 national sport policy. The document advocates increasing collaboration between sport and environmental organizations and highlights specific priority areas, such as:

"... the development and execution of public awareness programmes; highlighting issues related to sports and the environment; promoting and ensuring that greater prominence be given to the subject of sports and the effects of the environment in policy and strategic documents being developed or under revision; and that programmes geared to individual and institutional capacity building be introduced in the sports sector regarding the introduction of the Environmental Management System (EMS) and other critical strategies." [35]

This vision of collaboration and advocacy between sport and environmentalism in Jamaica would seem to be, potentially, well suited for the SDP sector. Given, then, that the environment is more of a policy priority within the traditional sport development sector in Jamaica-whose mandate is the 
development of sporting infrastructure and pathways, rather than mobilizing sport to meet broader development goals-as opposed to SDP, there would also appear to be something of a divide between more traditional public policy development and the burgeoning SDP sector. In this sense, though it might be tempting to emphasize the failure of SDP advocates to recognize the importance of the environment and the threat posed by climate change, the lack of attention paid to this issue in countries, like Jamaica, is likely more an illustration of the fractured nature of the SDP sector and its lack of connections to broader public policy structures. It is due to this policy incoherence that issues, like environmental sustainability and responses to climate change, continue to be marginalized.

\subsection{Kosovo}

Like many other middle-income countries, Kosovo faces its own set of difficult environmental challenges. These relate, for example, to relatively low levels of effective waste management and recycling, high levels of air pollution by industry and vehicles, which would otherwise fail European Union (EU) emissions protocols, and weakly regulated construction projects, which lead to poor drainage and flooding. In Kosovo, there were two main international NGOs in the SDP field; like those in Jamaica, they had understandably focused on other priorities, notably peace-building, so did not have strong environmental themes or goals in their work. Where the physical environment did come into play, it was as a more 'practical' concern, with, for example, volunteers clearing away stones or debris on outdoor playing surfaces before sports events could take place.

There is clear scope for the physical environment to develop into a more prominent SDP theme in Kosovo. One of the SDP NGOs engages already with a wide range of themes, including peace-building, gender empowerment, disability, and the social integration of the heavily marginalized. In some contrast, the other leading Kosovo NGO is focused, essentially, on cross-community relationships in this post-conflict setting. Both organizations are hard working, widely respected and long established in Kosovo and so would have the potential scope to put greater emphasis on the physical environment as a theme for intervention. This could be achieved, as a first measure, by ensuring education on waste management; young SDP volunteers and participants might be given regular sessions on environmental issues, with a view towards changing behaviour, for example in the disposal of waste from consumer items (e.g., the packaging for lunch packets, juice boxes, cigarette ends, etc.). On some occasions during our fieldwork, local NGO volunteers could be seen throwing away plastic cups or food wrapping for later collection, rather than visibly promoting the habit of directly disposing of these materials in identified waste bins.

In wider Kosovan society, we found a lack of education on the causes of pollution in key areas, such as industry and transport. Thus, there would be scope for SDP NGOs to highlight these issues with young people and local communities, and to enable these programme 'user groups' to identify ways to respond. At a practical level, this may, ultimately, lead to SDP programmes including activities that engage local volunteers and user groups to participate in community rubbish-clearing, an approach that has been used elsewhere in the SDP sector, notably by the Mathare Youth Sport Association (MYSA) in the Mathare slum of Nairobi, Kenya [36]. In this approach, sport offers a means of incentivising participants and/or teams to clear rubbish, for example by awarding points to teams that undertake this work. To go alongside this bottom-up, grassroots work, SDP NGOs may also pursue impact on environmental issues through top-down, policy-focused engagement. This latter focus might include developing public dialogue or campaigns with the government and the main financial supporters of Kosovo (notably, international governmental organizations and national embassies) to take seriously issues of environmental sustainability. It would also involve further extending the important work of these NGOs in enabling young people and local communities to become more effective public actors and policy advocates among key political, legal, and commercial decision-makers.

For a small country where social connections are important, and with the presence of SDP NGOs that are largely creative in terms of activities, themes, and social capital, it seems reasonable to expect a larger engagement with environmental issues. One advantage to doing so in a post-conflict setting, 
such as Kosovo, is that such 'green issues' are, potentially, less contentious than other SDP themes, particularly across different ethno-national communities. Indeed, at least in theory, the issue of the physical environment could enable the development of cross-community activity with a common focus.

\subsection{Rwanda}

Rwanda's development agenda has been highly focused on creating a sustainable, middle-income economy and society since the 1994 genocide that took place in the country. Indeed, under the leadership of President Paul Kagame, the East African country has committed significant time and resources to planning a prosperous future. A 2000 document, produced by the Ministry of Finance and Economic Planning, established a framework and targets for Rwanda's development. Entitled Vision 2020, the report highlighted six primary pillars of development: 1. Good governance and a capable state, 2 . human resource development and a knowledge-based economy, 3. a private sector-led economy, 4. infrastructure development, 5. productive and market-orientated agriculture, and 6. regional and international economic integration [37] (p. 13). These pillars are presented as integral to Rwanda's future position as an economically and politically stable and prosperous nation within the region and the world. Importantly, within the context of this report, the 'Protection of the environment and sustainable natural resource management' is considered a crosscutting theme. The specific commentary surrounding the physical environment within the report highlights the importance of maintaining Rwanda's diverse natural resources:

"The major problem in the field of environmental protection in Rwanda is the imbalance between the population and the natural resources (land, water, flora and fauna and non-renewable resources, which have been degrading for decades). This degradation is observed through massive deforestation, the depletion of bio-diversity, erosion and landslides, pollution of waterways, and the degradation of fragile ecosystems, such as swamps and wetlands." [37] (p. 22)

With this perspective in place, Kagame passed a series of laws, with the goal of keeping Rwanda clean. Indeed, our fieldwork highlighted the cleanliness of Kigali, Rwanda's capital, an observation supported by a group of NGO workers who described Rwanda as 'Africa-like' due to its pristine and groomed landscape. Notably, the tradition of 'Umuganda' has been revived. Umuganda loosely translates as coming together for a common purpose and entails a compulsory day of cleaning on the last Saturday of each month. All Rwandans are expected to clean their homes and the surrounding open spaces to maintain the expected level of cleanliness. Another, more specific, environmental development has been that, following changes in law, plastic bags have, effectively, disappeared from Rwandan society.

With such environmental concerns and localised small-scale solutions in place, we sought to understand if and how environmentalism was perceived, promoted, or enforced within the SDP sector in Rwanda. We observed one local NGO directing a football curriculum delivered by international partners, with themes and content designed to reflect local priorities. The social development objectives of the programme included conflict resolution, gender equity, health, and HIV awareness. In terms of process, the local leader of the NGO explained the issues on the ground and the priorities of the locals and the international partners would respond with the appropriate sports-based curriculum. Our research found that environmental concerns were not explicitly raised throughout the three-week delivery of the programme, but environmentally friendly activity was expected by participants. In some respects, this was not surprising; despite the priorities of the government to maintain and develop Rwanda's natural resources, at the local level people primarily understood their roles in environmental sustainability to be keeping Rwanda clean, an act that, in turn, demonstrates adherence to the expectations of those in positions of authority. The programme's participants would, therefore, clean the football pitches without prompt after training; plastic water bottles were cleared and any other litter was removed. There was, in this sense, little endeavour to 'educate' young sports participants 
on the gains to be made through everyday waste management. Rather, a 'top-down' approach was employed, whereby sport was connected to social expectations that are deeply engrained.

\subsection{Sri Lanka}

The current social and environmental context in Sri Lanka sees local actors pursuing opportunity amidst the aftermath of violence and tragedy. The 1983-2009 violent civil conflict and the 2004 Tsunami that devastated the region have clearly shaped current development work, as well as local activities within the SDP sector. In our fieldwork, we worked closely with a local NGO supporting development in the country; in the words of its founder:

The best thing to happen in this area (south region of the island) was the Tsunami, it was a disaster at the time for those who lost their lives and their homes but without the Tsunami we could not have accomplished the things we have. Because of the Tsunami people helped from all over the world, they donated money, equipment and helped us rebuild but better than before.

Notably, sport was one of the primary development strategies and priorities for this organization and was positioned as both an opportunity for the physical re-development of local land and for sustaining donors and attracting new ones. The destruction caused by the Tsunami facilitated the building of a sports complex, including a cricket pitch, swimming pool, gym, guest housing, and a netball and volleyball court. Those who live in the surrounding areas also had their homes repaired or rebuilt and now rely on newly built medical facilities, a school, and informal education opportunities. In this way, in the aftermath of conflict and disaster, environmental concerns constitute an important part of the development agenda for this local NGO. As a result, alongside the significance afforded to its sports programmes, the organization lists 'Environmental Management' as one of its objectives.

The main environmental goal was to ensure that every family had access to appropriate services, including sanitation, electricity, and clean water. This goal continues to be especially focused on in Sri Lanka's rural communities and the areas in the North and East that were most affected by conflict, many of which are still in an active recovery phase. The organisation claims that the 'sustainability of the rural environment is fundamental to the development of the village as part of the global community'. With this priority embedded in the ethos of the organisation, the environmental management strategy has five main commitments: Recycling; establishing home gardens; raising awareness of the local environment; tree planting to replenish foliage and protect vulnerable coastal areas and inland waterways; and bio-gas as an alternative fuel for cooking. In recent years, the organisation has distributed over 1000 solar powered bulbs to families in the north of the island.

While the actions of this NGO are notable for including both sport and environmental sustainability within a single organizational structure, a clear disconnect exists between the commitments to sports programmes and to environmental management. That is, the two goals operate largely in isolation, with little strategic or sustained interaction. For example, while cricket draws large numbers of participants and spectators from various social backgrounds, ethnicities, and ages in ways that support the goal of post-conflict reconciliation, such sport programmes rarely include any focus on environmental sustainability or the connections between sport and the environment. In this sense, even though an organization may include both sport and environmental concerns, this does not necessarily or inevitably equate to a strategic or conceptual linkage between the two issues within the context of SDP.

\subsection{Zambia}

The Zambia Environmental Management Agency (ZEMA) has a mission, ‘To safeguard human welfare and the environment, through effective environmental management for present and future generations.' [38] Yet, the greater Lusaka region has struggled to turn the goals of environmental sustainability into practice. 
On the one hand, large NGOs, like UNICEF, have developed programmes to educate youth on environmental issues. For example, according to its website, Unite4Climate Zambia 'is one of UNICEF's signature child-led advocacy programmes. It partners with young people in all of the country's nine provinces to combat climate change and is helping to empower and inspire thousands of children' [39]. Programmes such as this aim to create awareness of environmental issues that impact upon health and the sustainability of industries, such as agriculture, but there is a tenuous link, at best, between such large-scale programmes and practices on the ground.

This gap can be seen in the SDP sector. While relatively large NGOs, such as Sport in Action (Zambia), run successful programmes around basketball, football, and volleyball and the physical environments, these programmes have little in the way of an environmental focus or positive impact. Similarly, smaller Social Movement Organisations (SMO) operating in the SDP sector have done little to promote an environmental consciousness, though they have been faced with significant concerns over litter and sanitation. During our research, often, sporting fields had to be swept of litter before activities could take place and fields were marked by hazardous materials, like broken glass or metal. Notably, the potential risks from the physical hazards in the environment of the compounds did not discourage the children from being physically active.

That said, SMOs did contribute to cleaning the physical environment by using certain forms of litter to make sporting equipment. A good example of this is the footballs that were made entirely out of unwanted or worn out plastic bags. While high quality sporting equipment was valued, it was a luxury for many of the compound-based grassroots SMOs. As a result, organisers were actively encouraging the children to bring unwanted household materials, such as worn out plastic bags, to events so that these could be crafted into footballs and other sporting materials. This shows how the community SMOs are willing to exploit the relatively meagre resources that they have to provide equipment that might, in some way, go towards enhancing the lives of the underprivileged children with which they work in a voluntary capacity.

\section{Discussion}

In the penultimate section of this paper, we draw on the above insights from the field to offer some discussion regarding the emerging place of the physical environment within SDP research and the relationship between environmentalism and SDP activity. In so doing, we attend to three specific themes: The implications of local interpretations, the broader politics of environmentalism and policy making, and the importance of social theory.

In terms of local perspectives, when attempting to understand the environment within SDP activities, terminology and conceptualization are clearly important, as are issues of scale. Our research shows that the physical environment and environmental sustainability are understood differently in different places of SDP. In some cases, the role of sport is seen as a catalyst to support behaviour change and eco-friendly activities, like clean-up. This is a somewhat different approach and orientation than seeing a role for sport in securing long-term sustainable development. The key point is that the physical environment, and environmentalism, are broad terms in the SDP sector, and ones that are likely to be contested as a result. In this sense, scholars would do well to consider the ways in which different SDP organizations approach the physical environment differently—including, in some cases, by considering it not at all-and the implications of these varying understandings of the environment's importance and significance. In turn, scholars may need to acknowledge that the environmental mandate underpinning much of the SDGs does not necessarily filter into SDP activity daily, despite the rhetorical and political connections between sport and the UN's 2030 Agenda.

In terms of politics, then, several points are worth discussing. The first, we believe, is that, as much as the physical environment and issues of sustainability have become important topics, and even priorities, within international development, they are still often seen to be in conflict with other central development goals, notably economic growth. That is, even though the economic costs of climate change and its effects are becoming increasingly clear, there is still a sense that the 
choice to focus on the environment necessitates a choice not to focus on growth [40]. Given the significant influence of corporations on the SDP sector, and the regular positioning of SDP as a form of Corporate Social Responsibility [41], it is reasonable to suggest that one of the challenges for the integration of environmentalism within the sector is to move beyond such zero-sum thinking. While the idea of compatibility between ecology and the physical environment is not new in development thinking [42,43], it may be another area where the SDP sector can 'catch up' to development thinking more broadly. A second, but related, point is that while developing or marginalized countries are already starting to disproportionately bear the costs of a changing climate, they are also the ones who can least afford to ignore the promises of economic growth [44]. Thus, for the physical environment to become an important aspect of SDP, there will need to be a wider recognition of the various economic priorities and pressures that are to be found across different communities in developing countries.

In turn, the lack of attention paid to the environment within SDP may highlight the recurring tension in the sector between sport development and sport for development. In the former, the goal is to develop sport systems and opportunities for sporting participation and success, while the latter is concerned with using sport to meet development goals that extend beyond sport. While the two approaches and sectors are different, they inevitably overlap and can often be viewed externally as part of the same policy area. However, given that the sport industry's environmental record has come under criticism [8], it may seem (both within SDP and from outsider perspectives) that SDP is not ideally positioned to contribute to environmental issues. In this sense, for SDP to embrace ecological sustainability as part of its core mandate, it may be helpful—or even necessary—for it to be accompanied by renewed and/or increased commitments to the environment within the broader sport sector itself. Thus, the ongoing attempt to reform sport's poor environmental track record remains an important part of the place of the environment within SDP.

The question also remains as to how best to integrate environmental sustainability into the SDP sector given its rather disparate set of policy priorities. This issue of policy coherence is increasingly a challenge for SDP as its scope and reach present a strength in terms of relevance, but also a challenge in relation to its focus, expertise, and effectiveness [45]. Such issues of coherence can also be seen within the SDGs themselves, which significantly broadened the scope of the UN's development mandate relative to the MDGs, but, in so doing, arguably, blurred the focus of development. A key question, then, is: Would the SDP sector risk negatively affecting its core competencies (such as gender empowerment, health promotion, youth interventions) by attempting to make the environment one of its priorities? On the other hand, given the urgency and significance of climate change, can SDP reasonably afford not to engage with this crucial issue? Such issues are worthy of ongoing attention as the SDP sector evolves, particularly within the context of the 2030 Agenda.

In addition to these political issues, social scientists interested in understanding the place of the physical environment within the SDP sector would also do well to consider different theoretical insights. At least two are relevant here. The first is what might be called 'benign governmentality'. Governmentality theory is drawn from Foucault [46,47] and points to how the conduct of different populations is conducted 'at a distance', for example through the exercise of particular social policies. In the neo-liberal context, some literature on SDP and the wider development field has pointed to how forms of governmentality seek to direct individuals and social groups towards being self-regulating, self-motivated, and competitive actors in the labour market and other markets, in contexts where welfare states have either been forced into retreat or have never been able to grow in the first instance [48,49]. NGOs might be seen as playing a crucial role here, for example, in the SDP sector, through cultivating these individual traits, and developing responsible, pliant, and motivated 'young leaders' who will secure the stable future of local areas (despite the difficult structural conditions that they might endure). This version of governmentality theory, thus, draws social scientists into looking at SDP's social role in a rather critical way. A different emphasis might help to develop a 'benign' governmentality theory, which identifies how conduct may be conducted to have more positive and enabling effects for populations, for example, in how young people may be socialised into 
taking greater care of their local physical environment. This does not necessarily replace the need to pursue broader, structural changes, for example, tackling pollution or directing international resources towards improving the physical environment. However, this approach to benign governmentality, which aligns with other normative arguments on civic virtue, highlights some of the positive benefits that may be produced and experienced at a micro level, particularly through the everyday activities within the SDP sector.

Second, and at a more macro level, the notion of ecological modernization is relevant and instructive. Ecological modernization refers to environmentalist activity that, ostensibly, aims to respond to ecological degradation, but does so primarily through technical improvements and refinements that allow basic social and political structures (notably, economic growth and capital accumulation) to continue apace [10]. To date, the notion of ecological modernization has been used to explain policy and activity in sport. In golf, for example, a main response to the negative effects of golf course building and maintenance has been to refine such practices, such as introducing less harmful pesticides, but has rarely, if ever, considered the possibility of not building golf courses at all [12]. From this perspective, environmental issues are taken on only to the extent that they do not significantly challenge or disrupt contemporary lifestyles and consumptive practices. This is increasingly an issue as sports, like golf, work to expand their global footprint and increase the number of people who play the sport. This perspective raises the question as to whether there is political will or palatability within the SDP sector to advocate for the kinds of environmental policies and practices that would call into question current levels or understandings of development itself, or whether SDP is committed to development that would see more and more of the world's population consume as First World subjects, an achievement that would likely preclude significant progress towards environmental sustainability.

\section{Conclusions}

In this paper, we have offered a series of theoretical and empirical insights designed to contribute to filling the lacuna around the place of the physical environment within the Sport for Development and Peace sector. We have argued that the physical environment is of crucial importance to international development and is taken up to an extent within SDP, though such processes differ significantly by region and in different geographical, social, and political contexts. In turn, we have argued for the importance of an appreciation of the politics of environmentalism that are likely to affect the ways that the physical environment is approached (or not) within SDP and have suggested two theoretical frameworks that social scientists might consider when exploring this issue.

To conclude, we highlight some of the research questions, which, within the confines of this paper, we have been unable to address fully and that are still to be pursued by scholars interested in the place of the physical environment within SDP. This series of questions is by no means exhaustive, but does illustrate the significance of the issue and the work still to be done to make sense of it from a social scientific perspective. First, as our fieldwork shows that different stakeholders in SDP see the issues of environmentalism and ecology differently, there is a need to understand how and why this diversity of perspectives comes about. In other words, what determines the disparate relevance or importance of the physical environment amongst various SDP stakeholders?

We also might ask how the broader politics of climate change play out in the SDP sector. That is, as the political and economic tensions about how to deal with the imminent threat of climate change are negotiated, what impact will this have on the SDP sector? Conversely, is there any role or impact that the SDP sector might have on advancing environmentalism within development more broadly?

Finally, what impact, if any, is the sustainability agenda of the SDGs having on the day to day practice of SDP around the world? While the inclusion of sport within the 2030 Agenda was a significant moment for advocates and policymakers within SDP, particularly those working at a global scale, it remains to be seen what effect, if any, this has had on quotidian SDP policy and practice. While there is evidence that northern funders of SDP can impact the work that goes on in developing countries, the extent to which this holds for the SDGs and issues of the physical environment remains 
to be seen. Overall, then, significant work remains to be done to establish the place of the physical environment within the global Sport for Development and Peace sector, though there is no doubt that this task should not be overlooked by the sector any longer.

Author Contributions: Giulianotti led the initial conceptualization of the paper and was responsible for funding acquisition; subsequent development of the paper was shared across the four authors.

Funding: This research was funded by the UK Economic and Social Research Council grant number ES/L002191/1.

Conflicts of Interest: The authors declare no conflicts of interest.

\section{References}

1. Ingold, T. The Perception of the Environment: Essays on Livelihood, Dwelling and Skill; Routledge: London, UK, 2011; p. 20.

2. Commonwealth Secretariat. Commonwealth Analysis: Sport for Development and Peace and the 2030 Agenda for Sustainable Development; Commonwealth Secretariat: London, UK, 2015.

3. Coalter, F. Sport for Development: What Game Are We Playing? Routledge: London, UK, 2013.

4. Schulenkorf, N.; Adair, D. (Eds.) Global Sport-for-Development: Critical Perspectives; Palgrave MacMillan: Basingstoke, UK, 2014.

5. Levermore, R.; Beacom, A. (Eds.) Sport and International Development; Palgrave Macmillan: Basingstoke, UK, 2009.

6. Collison, H. Youth and Sport for Development: The Seduction of Football in Liberia; Palgrave: Basingstoke, UK, 2016.

7. Darnell, S. Sport for Development and Peace: A Critical Sociology; Bloomsbury: London, UK, 2012.

8. Miller, T. Greenwashing Sport; Taylor \& Francis: London, UK, 2017.

9. Cantelon, H.; Letters, M. The making of the IOC environmental policy as the third dimension of the Olympic movement. Int. Rev. Sociol. Sport 2000, 35, 294-308. [CrossRef]

10. Mol, A.P.J. Sustainability as global attractor: The greening of the 2008 Beijing Olympics. Glob. Netw. 2010, 10, 510-528. [CrossRef]

11. Lenskyj, H.J. Sport and corporate environmentalism: The case of the Sydney 2000 Olympics. Int. Rev. Sociol. Sport 1998, 33, 341-354. [CrossRef]

12. Millington, B.; Wilson, B. The Greening of Golf: Sport, Globalization and the Environment; Manchester University Press: Manchester, UK, 2016.

13. Mallen, C. Robustness of the Sport and Environmental Sustainability Literature and Where to Go from Here. In Sport and the Environment; McCullough, B.P., Kellison, T.P., Eds.; Routledge: London, UK, 2017.

14. Giulianotti, R.; Collison, H.; Darnell, S.; Howe, P.D. Sport for a Better World Research: Implications for Commonwealth Sport Policy-Makers. In Proceedings of the 8th Commonwealth Sports Ministers' Meeting, Rio de Janeiro, Brazil, 4 August 2016.

15. Giulianotti, R.; Collison, H.; Darnell, S.; Howe, P.D. Sustainable Development through Sport? Critical insights from an international research project on the sport for development and peace sector. In Proceedings of the Development Studies Association Annual Conference, University of Oxford, Oxford, UK, 12-14 September 2016.

16. Giulianotti, R.; Collison, H.; Darnell, S.; Howe, P.D. Sport for a Better World? A Social Scientific Investigation of the SDP Sector. In Proceedings of the Symposium 'Sport for a Better World?', Commonwealth Secretariat, London, UK, 23 May 2017.

17. Beck, U. Risk Society: Towards a New Modernity; Sage: London, UK, 1992.

18. Hajer, M.A. The Politics of Environmental Discourse: Ecological Modernization and the Policy Process; Clarendon Press: Oxford, UK, 1995.

19. Hannigan, J. Environmental Sociology; Routledge: London, UK, 2006.

20. Lubbers, E. Battling Big Business: Countering Greenwash, Infiltration, and Other Forms of Corporate Bullying; Common Courage Books: Monroe, ME, USA, 2002.

21. Yearley, S. The Green Case: A Sociology of Environmental Issues, Arguments and Politics; Routledge: London, UK, 2014.

22. United Nations (UN). Transforming Our World: The 2030 Agenda for Sustainable Development; UN: New York, NY, USA, 2015. 
23. Lindsey, I.; Chapman, T. Enhancing the Contribution of Sport to the Sustainable Development Goals; Commonwealth Secretariat: London, UK, 2017.

24. Levin, K.; Cashore, B.; Bernstein, S.; Auld, G. Overcoming the tragedy of super wicked problems: Constraining our future selves to ameliorate global climate change. Policy Sci. 2012, 45, 123-152. [CrossRef]

25. Redclift, M. Sustainable development. In The Companion to Development Studies; Desai, V., Potter, R., Eds.; Routledge: London, UK, 2014; p. 333.

26. Schulenkorf, N. The contributions of special events to sport for development programs. J. Sport Manag. 2016, 30, 629-642. [CrossRef]

27. Welty Peachey, J.; Cohen, A. Research partnerships in sport for development and peace: Challenges, barriers, and strategies. J. Sport Manag. 2016, 30, 282-297. [CrossRef]

28. Giulianotti, R.; Armstrong, G.; Hales, G.; Hobbs, D. Sport mega-events and public opposition: A sociological study of the London 2012 Olympics. J. Sport Soc. Issues 2015, 39, 99-119. [CrossRef]

29. Timms, J. The Olympics as a platform for protest: A case study of the London 2012 'ethical' Games and the play fair campaign for workers' rights. Leis. Stud. 2012, 31, 355-372. [CrossRef]

30. Eriksen, T.H. Small Places, Large Issues: An Introduction to Social and Cultural Anthropology, 2nd ed.; Pluto: London, UK, 2001.

31. Van Maanen, J. Tales of the Field: On Writing Ethnography; University of Chicago Press: Chicago, IL, USA, 2011.

32. See also Howe, P.D.; Morris, C. An exploration of the co-production of performance running bodies and natures within "Running Taskscapes". J. Sport Soc. Issues 2009, 33, 308-330. [CrossRef]

33. United Nations Development Programme. Coping with Climate Change; UNDP: New York, NY, USA, 2018.

34. Darnell, S.C.; Black, D.R. Mainstreaming sport into international development studies. Third World Q. 2011, 32, 367-378. [CrossRef]

35. Jamaican Ministry of Youth, Sports, and Culture. National Sports Policy for Jamaica; Jamaican Ministry of Youth, Sports, and Culture: Kingston, CA, USA, 2018.

36. Willis, O. Sport and development: The significance of Mathare youth sports association. Can. J. Dev. Stud./Revue Canadienne d'Études Du Développement 2000, 21, 825-849. [CrossRef]

37. Republic of Rwanda Ministry of Finance and Economic Planning. Vision 2020; Rwanda Ministry of Finance and Economic Planning: Kigali, Rwanda, 2000.

38. Zambian Environmental Management Agency. About Us; Zambian Environmental Management Agency: Lusaka, Zambia, 2018.

39. United Nations International Children's Emergency Fund. Unite4 Climate Zambia; UNICEF: New York, NY, USA, 2018.

40. Raworth, K. Doughnut Economics: Seven Ways to Think Like a 21st Century Economist; Chelsea Green: London, UK, 2017.

41. Levermore, R. CSR for development through sport: Examining its potential and limitations. Third World $Q$. 2010, 31, 223-241. [CrossRef]

42. Cato, M.S. Environment and Economy; Routledge: London, UK, 2011.

43. Giddings, B.; Hopwood, B.; O’Brien, G. Environment, economy and society: Fitting them together into sustainable development. Sustain. Dev. 2002, 10, 187-196. [CrossRef]

44. Parks, B.; Roberts, J.T. Globalization, vulnerability to climate change and perceived injustice. Soc. Nat. Resour. 2006, 19, 337-355. [CrossRef]

45. Lindsey, I.; Darby, P. Sport and the sustainable development goals: Where is the policy coherence? Int. Rev. Sociol. Sport 2018. [CrossRef]

46. Dean, M. Governmentality: Power and Rule in Modern Society; Sage: London, UK, 2010.

47. Foucault, M. The subject and power. Crit. Inq. 1982, 8, 777-795. [CrossRef]

48. Li, T.M. The Will to Improve: Governmentality, Development and the Practice of Politics; Duke University Press: Durham, NC, USA, 2007.

49. Sharma, A. Logics of Empowerment: Development, Gender, and Governance in Neoliberal India; University of Minnesota Press: Minneapolis, MN, USA, 2008.

(C) 2018 by the authors. Licensee MDPI, Basel, Switzerland. This article is an open access article distributed under the terms and conditions of the Creative Commons Attribution (CC BY) license (http:/ / creativecommons.org/licenses/by/4.0/). 